\title{
Vitaceae endémicas del Perú
}

Blanca León ${ }^{1,2}$

${ }^{1}$ Museo de Historia Natural, Av. Arenales 1256, Aptdo. 14-0434, Lima 14, Perú

2 Plant Resources Center, University of Texas at Austin, Austin TX 78712 EE.UU.

blanca.leon@mail.utexas.edu

\section{Resumen}

La familia Vitaceae es reconocida en el Perú por presentar tres géneros y 31 especies (Brako \& Zarucchi, 1993; Ulloa Ulloa et al., 2004), todos bejucos y lianas. En este trabajo reconocemos un endemismo en el género Cissus. Esta especie ha sido encontrada en la región Bosques Húmedos Amazónicos, a 200 m de altitud. No se encuentra representada dentro del Sistema Nacional de Áreas Naturales Protegidas por el Estado.

Palabras claves: Vitaceae, Cissus, Perú, endemismo, plantas endémicas.

\section{Abstract}

The Vitaceae are represented in Peru by three genera and 31 species (Brako \& Zarucchi, 1993; Ulloa Ulloa et al., 2004), all vines and lianas. Here we recognize one endemic species in the genus Cissus. This species is found in Humis Lowland Amazonian Forests region, to $200 \mathrm{~m}$ elevation. It has not been recorded within Peru's protected areas system.

Keywords: Vitaceae, Cissus, Peru, endemism, endemic plants.

\section{Cissus longicymosa Lombardi}

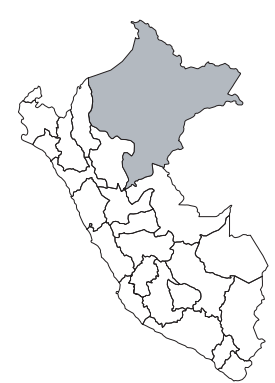

\section{DD}

Publicación: Fl. Neotropica 80: 112113, f. 53. 2000.

Colección tipo: A.H. Gentry et al. 21999

Herbarios: F, MO.

Nombre común: Desconocido.

Registro departamental: LO.

Regiones Ecológicas: BHA; $200 \mathrm{~m}$.

SINANPE: Sin registro.

Herbarios peruanos: Ninguno.

Observaciones: Liana conocida sólo de la localidad original, la cual se halla en el límite con Colombia, donde fue registrada en 1978. Se desconoce el estado de sus poblaciones. 